\title{
An Optimized Highly Efficient RF Power Amplifier for WLAN System Application
}

\author{
Mohammed H. Ali, C. K. Chakrabarty, \& Mithaq H. Raheema \\ Department of Electronics and Communication Engineering \\ University Tenaga Nasional, Selangor 43009, Malaysia
}

Received: November 22, 2011

Accepted: December 12, $2011 \quad$ Published: Feburary 1, 2012

doi:10.5539/mas.v6n2p2

URL: http://dx.doi.org/10.5539/mas.v6n2p2

\begin{abstract}
The class-AB/ F power amplifier (PA), Class F is commonly understood to be a switching PA, but in fact, it can also be a transconductance PA, depending on how hard the active device is driven. This paper presents the design a multistage class $\mathrm{AB} /$ Inverse $\mathrm{F}$ power Amplifier with high power added efficiency (PAE) and acceptable linearity for the WLAN applications. The effectiveness of the proposed controller has been verified by comparing proposed method with another methods using simulation study under a variety of conditions. The proposed circuit operation for a WLAN signal delivers a power-added efficiency (PAE) of $43.9 \%$ is measured at 32.1-dBm output power and linearity of inverse class F displays the simulation result of 1-dB compression output power of $17.5 \mathrm{dBm}$ at $-22.4 \mathrm{dBm}$ input power. Finally, the proposed PA is show a good and acceptable result for the WLAN system.
\end{abstract}

Keywords: Power amplifier, WLAN system, Harmonic terminations, Biasing voltage

\section{Introduction}

The integration of wireless communication systems requires stringent capabilities in terms of linearity and efficiency. It is well known that the power amplifier (PA) need to amplify signals efficiently to increase the battery life that typically deliver their highest efficiency at maximum output power in linearity becomes significant (Zhen L., et al., 2002).

Recently, power amplification techniques with inherently more power efficient have been researched to satisfy the requirements (Bing B., \& Jayant N., 2002; Bakkaloglu B., \& Fontaine P. A., 2005). Such techniques are included load modulation technique, switching mode amplifiers (Nam J., 2005), envelope elimination and restoration (Raab, F. H., et al., 1998), the multi-modes and multiband of operation and envelope tracking (Tsai Pi. H., et al., 2005). The Doherty Power Amplifier is a promising candidate with advantages of high PAE, low cost and simple construction (Kimball D. F., et al., 2006; McMorrow R. J., et al., 1994). Another many advanced techniques have been reported (Kenington P. B., 1999; Matsuge K., et al., 2004) for improve performance of PA however there are many drawbacks such as envelop tracking technique and weighted polynomial digital pre-distortion technique but still these techniques including complex circuit configuration, modest enhancement and high cost.

This paper focus on control the shape and overlap of the drain voltage and/or current waveforms for class-AB/IF power amplifier using appropriate gate biasing and harmonic terminations. First, exploit the harmonic contents so the loss in the active device is minimized. Second, bias the amplifier toward class $A B / A(A B$ or $A)$ to improve the linearity. Finally, the simulation result show that proposed PA are significantly improvement the linearity, efficiency and output power can be achieved with proper harmonic terminations and proper biasing voltage.

\section{Proposed Circuit Design}

A schematic of the designed PA is shown in Figure 1. The output stage of the power amplifier is a class-AB/F topology with the harmonic control circuits, and the driver multistage is a pre-amplifier that is composed of a class-F amplifier. The specifications of the proposed Power Amplifier are calculated based on (Point R., 2003). Some of the key specifications in the design of this PA are its frequency of operation, gain, output power level, and bias voltages are adaptively modified of the input/output impedances. Traditionally, all the impedances of any RF block are terminated with $50 \Omega$, especially to aid in the testing of these blocks. In addition, it is easy to see that with the load modulation can be carried out in multistage with different control voltage profiles. 


\section{Simulation Results}

To enable to test the proposed class $\mathrm{AB} /$ Inverse $\mathrm{F}$ amplifier, closer examination of the voltages and currents of WLAN amplifier is required. Figure 2 shows the voltage and current waveforms at the drain terminal for the class AB output stage of 3-stages WLAN PA. Recall that this PA provides output power of $17.8 \mathrm{dBm}$, power gain of $30.7 \mathrm{~dB}$, and PAE of $29.4 \%$.

Figure 3 shows the simulation response of the proposed class AB/Inverse $\mathrm{F}$ amplifier at input power of $-13 \mathrm{dBm}$. Higher output power of $19.2 \mathrm{dBm}$ is provided with a power gain of $32.1 \mathrm{~dB}$ and PAE of $38.7 \%$.

Figure 4 shows the 1-dB compression output power for 3-stages WLAN PA, with output stage of different biasing gate voltages for comparison. The linearity of power amplifier in the proposed mode can be expected to be higher than the traditional class $\mathrm{F}$.

Figure 5 shows this principle, when class $\mathrm{AB} / \mathrm{F} 1-\mathrm{dB}$ compression output power is $16.7 \mathrm{dBm}$ which represents good linearity, compared with that of $10.3 \mathrm{dBm}$ for the traditional class $\mathrm{F}$ amplifier. In this proposed switch mode and with the assistance of harmonic impedance components at the output, to improve the efficiency, the $1-\mathrm{dB}$ compression can be increased as a criterion of linearity improvement.

Figure 6, the linearity of inverse class F displays the simulation result of 1-dB compression output power of 17.5 $\mathrm{dBm}$ at $-22.4 \mathrm{dBm}$ input power. This value represents a very important indicator to combine linearity improvement with all others output requirements such as output power, power gain, and PAE.

Finally, Figure 7 shows testing the simulation response of drive a proper input signal to the output stage with different biasing gate voltages, in which, 3-stages WLAN PA is designed with class AB biasing for each stage in addition to the second and third harmonic impedance components at the output terminal of the output stage. The power-added efficiency was measured to be $43.8 \%$, a very good value, indicating the advantage of these proposed design steps.

\section{Conclusion}

In this paper, Class $\mathrm{AB} / \mathrm{F}$ is studied the ideal theoretical solution for the efficiency-linearity tradeoff and have proposed a new concept of a class AB/IF PA $2.4 \mathrm{GHz}$ using multistage technique. However, the performance of this amplifier relies heavily on the realization of the harmonic traps and the input biasing voltage. As for the class-F amplifier, harmonic terminations at the drain are important to improve both efficiency and output power. For the third-harmonic resonator to generate a third-harmonic component of voltage, it requires third-harmonic current which does not exist. The simulation result showed that the proposed significantly improved the efficiency over a broad average output power compared to the conventional balanced amplifier.

\section{References}

Bing, B., \& Jayant, N. (2002). A cellphone for all standards. IEEE Spectr., 39(5), 34-39. http://dx.doi.org/10.1109/6.999792

Bakkaloglu, B., \& Fontaine, P. A. (2005). Multi-mode, multi-band RF transceiver circuits for mobile terminals in deep-submicron CMOS processes. In Proc. IEEE Radio Freq. integrated Circuits Symp., 483-486. http://dx.doi.org/10.1109/RFIC.2005.1489851

Kenington, P. B. (1999). High-linearity RF Amplifier Design, Artech House, Norwood, MA.

Kimball, D. F., Jeong, J., Hsia, C., Draxler, P., Lanfranco, S., Nagy, W., Linthicum, K., et al. (2006). High-efficiency envelope tracking W-CDMA base-station amplifier usingGaN HFETs. IEEE Trans. Microw. Theory Tech., 54(11), 3848-3856. http://dx.doi.org/10.1109/TMTT.2006.884685

Matsuge, K., Hiura, S., Ishida, M., Kitahara, T., \& Yamamoto, T. (2004). Full RF module with embedded filters for $2.4 \mathrm{GHz}$ and $5 \mathrm{GHz}$ dual band WLAN applications. IEEE MTT-s, 2, 629-632. http://dx.doi.org/10.1109/MWSYM.2004.1336064

McMorrow, R. J., Upton, D. M., \& Maloney, P. R. (1994). The microwave Doherty amplifier. IEEE MTT-S Int. Microwave Symp. Dig., 1653-1656. http://dx.doi.org/10.1109/MWSYM.1994.335123

Nam, J., Shin, J. H., \& Kim, B. (2005). A handset power amplifier with high efficiency at lowlevel using load modulation technique. IEEE Trans. Microw. Theory Tech., 53(8), 2639-2644. http://dx.doi.org/10.1109/TMTT.2005.852745

Point, R. (2003). An RF CMOS Transmitter Integrating a Power Amplifier and a Transmit/Receive Switch for 802.11b Wireless Local Area Network Applications. IEEE Radio Frequency Integrated Circuits Symposium, 431-434. http://dx.doi.org/10.1109/RFIC.2003.1213978 
Raab, F. H., Sigmon, B. E., Myers, R. G., \& Jackson, R. M. (1998). L-band transmitter using KahnEER technique. IEEE Trans. Microw. Theory Tech., 46(12), 2220-2225. http://dx.doi.org/10.1109/22.739200

Tsai, Pi. H., Metzger, A. G., Zampardi, P. J., Iwamoto, M., \& Asbeck, P. M. (2005). Design of highefficiency current-mode class D amplifier for wireless handsets. IEEE Trans. Microw. TheoryTech., 53(1), 144-151. http://dx.doi.org/10.1109/TMTT.2004.839327

Zhen, L., Wenan, Z., Junde, S., \& Chunping, H. (2002). Consideration and research issues for the future generation of mobile communication. In Proc. IEEE Can. Elect. Comput. Eng. Conf., 6(1), 44-55. http://dx.doi.org/10.1109/CCECE.2002.1012933

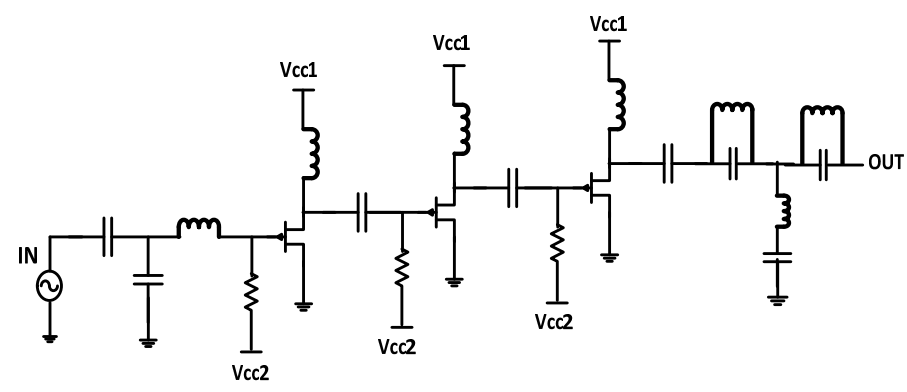

Figure 1. Optimized PA schematic

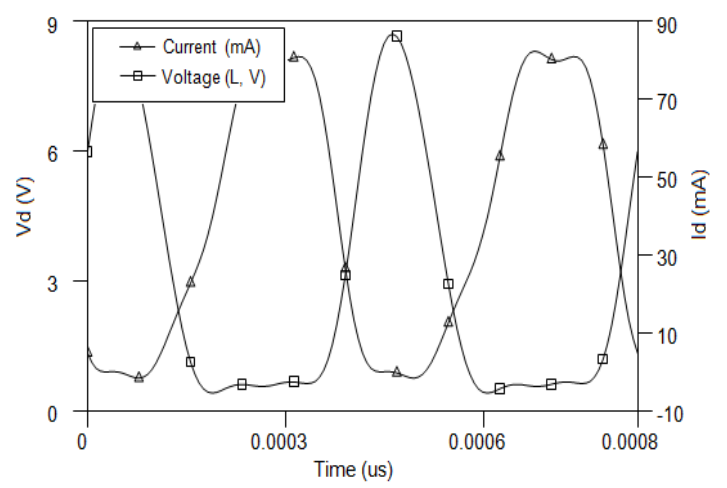

Figure 2. The voltage and current waveforms at the drain terminal

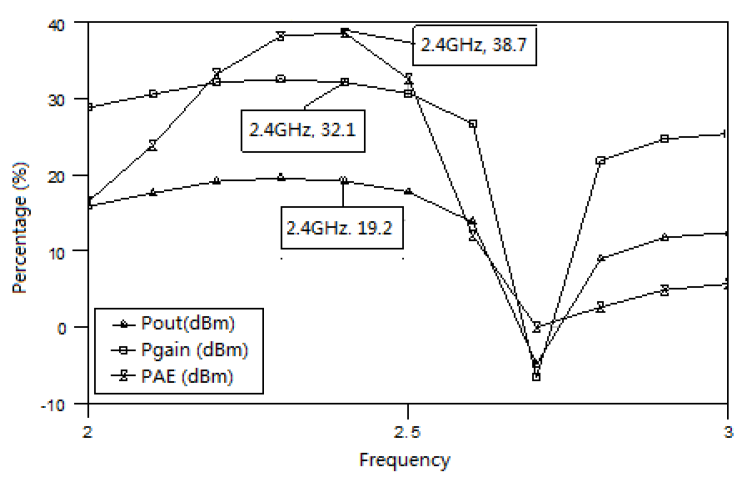

Figure 3. Percentage output power, power gain, and power added efficiency 


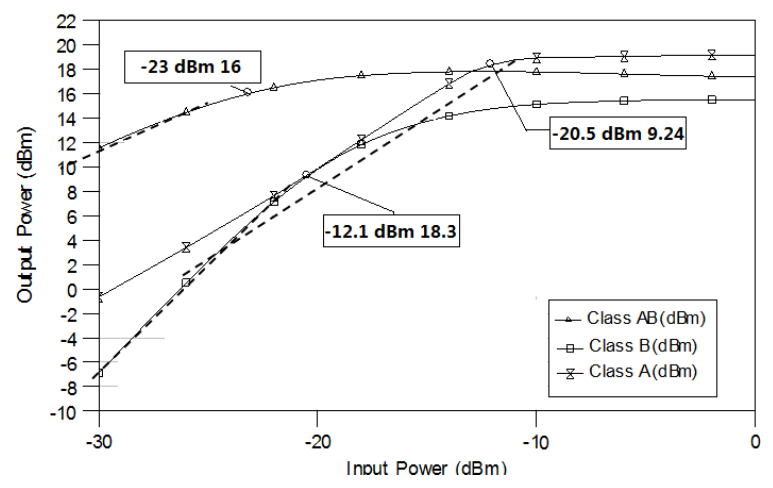

Figure 4. Compression 1-dB linearity output power of 3-stages WLAN PA

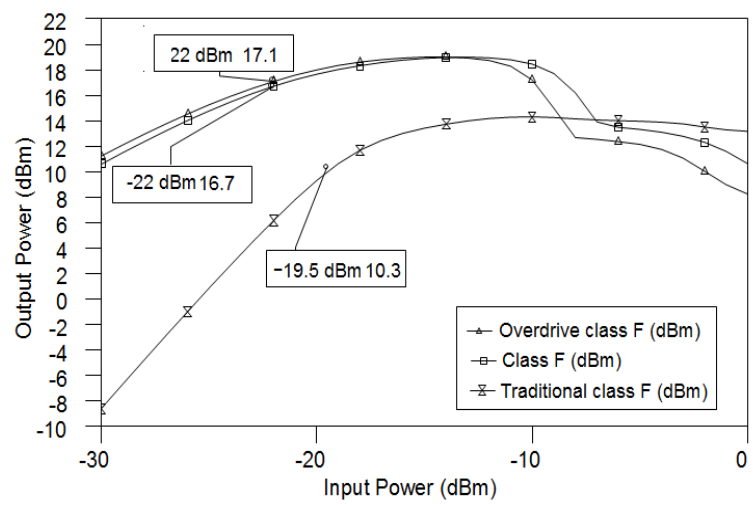

Figure 5. Compression 1-dB output power of 3-stages WLAN switch PA

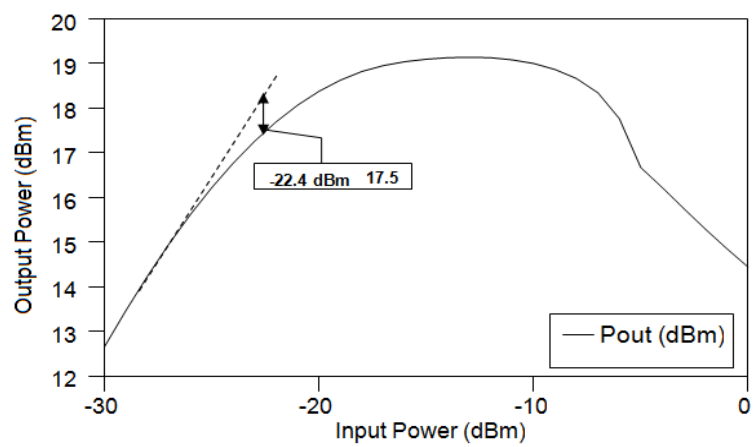

Figure 6. Compression 1-dB output power of proposed class AB/Inverse F 3-stages WLAN PA

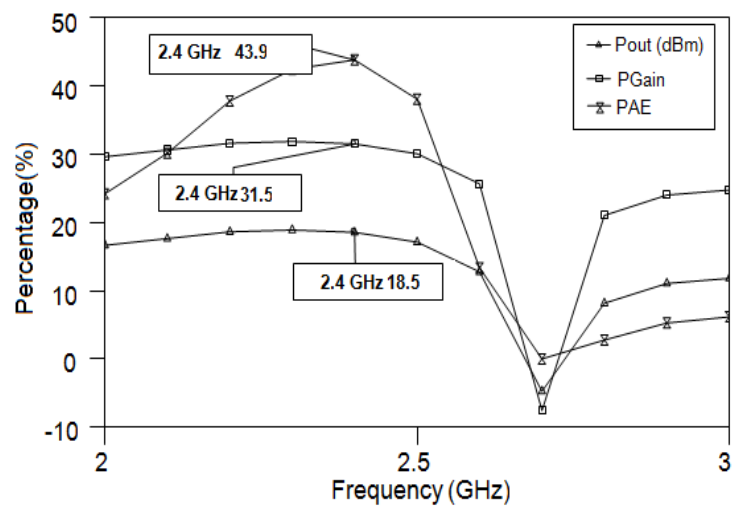

Figure 7. Added efficiency versus the input signal frequency 